\title{
Circadian feeding patterns of 12-month-old infants
}

Poh Hui Wee ${ }^{1}$, See Ling Loy ${ }^{2,3}$, Jia Ying Toh ${ }^{4}$, Elaine Kwang Hsia Tham ${ }^{4}$, Yin Bun Cheung ${ }^{5,6}$, Keith M. Godfrey $^{7,8}$, Peter D. Gluckman ${ }^{4,9}$, Seang Mei Saw ${ }^{10}$, Yap-Seng Chong ${ }^{4,11}$, Ngee Lek ${ }^{1,3}$, Jerry Kok Yen Chan ${ }^{2,3}$, Daniel Yam Thiam Goh ${ }^{12}$, Mary Foong-Fong Chong ${ }^{4,10,13}$ and Fabian Yap ${ }^{1,3,14 *}$ on behalf of the Growing Up in Singapore Towards Healthy Outcomes (GUSTO) study group

${ }^{1}$ Department of Paediatrics, KK Women's and Children's Hospital, Singapore 229899, Singapore

${ }^{2}$ Department of Reproductive Medicine, KK Women's and Children's Hospital, Singapore 229899, Singapore

${ }^{3}$ Duke-NUS Medical School, Singapore 169857, Singapore

${ }^{4}$ Singapore Institute for Clinical Sciences, Agency for Science, Technology and Research (A*STAR),

Singapore 117609, Singapore

${ }^{5}$ Duke-NUS Medical School, Center for Quantitative Medicine, Singapore 169857, Singapore

${ }^{6}$ Department for International Health, University of Tampere, Tampere 33014, Finland

${ }^{7}$ Medical Research Council Lifecourse Epidemiology Unit, University of Southampton, Southampton SO16 6YD, UK

${ }^{8}$ National Institute for Health Research Southampton Biomedical Research Centre, University of Southampton and University Hospital Southampton National Health Service Foundation Trust, Southampton SO16 6YD, UK

${ }^{9}$ Liggins Institute, University of Auckland, Auckland 1142, New Zealand

${ }^{10}$ Saw Swee Hock School of Public Health, National University of Singapore, Singapore 117549, Singapore

${ }^{11}$ Department of Obstetrics \& Gynaecology, Yong Loo Lin School of Medicine, National University of Singapore,

National University Health System, Singapore 119228, Singapore

${ }^{12}$ Department of Paediatrics, Yong Loo Lin School of Medicine, National University of Singapore, National University Health System, Singapore 119228, Singapore

${ }^{13}$ Clinical Nutrition Research Centre, Singapore Institute for Clinical Sciences (SICS), Agency for Science, Technology and Research (A*STAR), Singapore 117599, Singapore

${ }^{14}$ Lee Kong Chian School of Medicine, Nanyang Technological University, Singapore 636921, Singapore

(Submitted 1 November 2016 - Final revision received 28 April 2017 - Accepted 14 June 2017)

\section{Abstract}

Early life nutrition and feeding practices are important modifiable determinants of subsequent obesity, yet little is known about the circadian feeding pattern of 12-month-old infants. We aimed to describe the 24-h feeding patterns of 12-month-old infants and examine their associations with maternal and infant characteristics. Mothers from a prospective birth cohort study $(n$ 431) reported dietary intakes of their 12-month-old infants and respective feeding times using 24-h dietary recall. Based on their feeding times, infants were classified into post-midnight (00.00-05.59 hours) and pre-midnight (06.00-23.59 hours) feeders. Mean daily energy intake was 3234 (sD 950) kJ (773 (sD 227) kcal), comprising 51.8 (SD 7.8) \% carbohydrate, 33.9 (SD 7.2)\% fat and 14.4 (SD 3.2) \% protein. Mean hourly energy intake and proportion of infants fed were lower during post-midnight than pre-midnight hours. There were 251 (58.2\%) pre-midnight and 180 (41.8\%) post-midnight feeders. Post-midnight feeders consumed higher daily energy, carbohydrate, fat and protein intakes than pre-midnight feeders (all $P<0 \cdot 001$ ). The difference in energy intake originated from energy content consumed during the post-midnight period. Majority ( $n$ 173) of post-midnight feeders consumed formula milk during the post-midnight period. Using multivariate logistic regression with confounder adjustment, exclusively breast-feeding during the first 6 months of life was negatively associated with post-midnight feeding at 12 months (adjusted OR 0.31; 95\% CI 0.11, 0.82). This study provides new insights into the circadian pattern of energy intake during infancy. Our findings indicated that the timing of feeding at 12 months was associated with daily energy and macronutrient intakes, and feeding mode during early infancy.

Key words: Feeding patterns: Circadian feeding: Midnight feeding: Daily energy intake: Infancy

The first $1000 \mathrm{~d}$ of life, spanning from conception to 2 years of age, is recognised as a critical period of growth and development. As highlighted in the developmental origins of health and disease hypothesis, adverse exposures during this period of early programming and plasticity have long-term implications on later health ${ }^{(1)}$. It is well-established that early life nutrition is a key environmental factor that strongly influences the risk of developing CVD and metabolic diseases in adulthood ${ }^{(2)}$.

* Corresponding author: Dr F. Yap, email Fabian.Yap.K.P@singhealth.com.sg 
Substantial evidence indicates that fetal adaptive responses to a poor or overly rich perinatal environment may lead to long-term programming effects or plastic modifications of tissues and organs, thereby predisposing offsprings to a higher risk of chronic diseases ${ }^{(3-6)}$. It has also been proposed that these adaptations would only become detrimental when they do not match the predicted post-natal environmental conditions ${ }^{(6-8)}$.

Early life nutrition provides the essential building blocks for the healthy development of the brain, organs and immune system. Nature leads the first $500 \mathrm{~d}$ of the offspring's diet - the period from conception to approximately 6 months of age when the growing offspring is completely dependent on his/her mother for nutrition ${ }^{(9)}$. This adaptive nature of nutrition occurs via the placenta to the developing embryo and fetus, and then ideally via exclusive breast-feeding for the first 6 months of infancy $^{(9)}$. The next $150 \mathrm{~d}$ involves weaning, complementary feeding and the gradual transition towards culture-specific oral feeding. This period serves as a window of opportunity to establish long-term healthy food preferences and eating habits as the infant gets exposed to a wide variety of tastes and textures $^{(10)}$. The end of the first $650 \mathrm{~d}$ of life when the child turns 1 year old marks the end of infancy. It is the expected point of completion of weaning (i.e. end of the process of transitioning from a predominantly milk-based to a mainly solid-based diet) and the beginning of the cultivation of longterm eating habits. Beyond this stage, culture and environment increasingly become the main drivers of feeding practices. At 12 months, an infant's daily sleep/wake cycle is moderately stabilised with an increasing consolidation of sleep during the night compared with early infancy ${ }^{(11)}$, implying that consistent and stable daily feeding practices may be in place. As this transition point sets the foundation for later food choices and eating habits, infant feeding practices at 12 months deserve more attention.

Studies on the long-term consequences of feeding practices during early life stages have traditionally focused on breastfeeding ${ }^{(12,13)}$, macronutrient composition ${ }^{(14)}$ and amount of energy intake ${ }^{(15)}$. In recent years, there is accumulating evidence that the timing of energy intake itself may be of fundamental importance in the aetiology of obesity. Mice fed during the light phase, which corresponds to their biological night, gained more weight than those fed during the dark phase, independent of total energy intakes, locomotor activity and light/dark cycles ${ }^{(16,17)}$. In adults, temporal eating behaviours such as breakfast skipping and night eating syndrome have been positively associated with obesity ${ }^{(18-20)}$. Studies performed in children and adolescents are also consistent with the association between breakfast skipping and increased $\mathrm{BMI}^{(21,22)}$, suggesting that meal timing may also be relevant during the earlier stages of life.

Altogether, these studies highlight the associations between temporal pattern of energy intake and metabolic outcomes. Studies exploring eating behaviours and patterns in young children and adolescents are limited; those that investigated the temporal aspect of feeding looked only at single meal behaviours $^{(21,23)}$ instead of adopting a more holistic approach by considering the temporal pattern of energy intake across 24-h. In this study, we used data from a prospective cohort consisting of multi-ethnic Asian infants from Singapore, the
Growing Up in Singapore Towards healthy Outcomes (GUSTO) study, to describe the circadian feeding pattern of 12-month-old infants and associate their temporal feeding pattern with maternal and infant characteristics.

\section{Methods}

\section{Study design and participants}

Data were obtained from the GUSTO cohort. The details of the study methodology have been described elsewhere ${ }^{(24)}$. In brief, a total of 1237 singleton pregnant women aged 18 years and above were recruited in their first trimester ( $\leq 14$ weeks gestation based on ultrasound dating) at KK Women's and Children's Hospital and National University Hospital between June 2009 and September 2010. Only Singapore citizens or permanent residents with the intention to reside in Singapore for the next 5 years, and had spouses of the same race, both of whom had to be of a homogenous parental background of Chinese, Malay or Indian ethnicity were eligible for this study. Women on chemotherapy or psychotropic drugs, or had type I diabetic mellitus were ineligible. Written informed consent was obtained from each participant upon recruitment. This study was approved by the Centralised Institutional Review Board of SingHealth (reference 2009/280/D) and the Domain Specific Review Board of the Singapore National Healthcare Group (reference D/09/021). This study was registered at www.clinicaltrials.gov as NCT01174875.

\section{Maternal characteristics}

At recruitment and 26-28 weeks' gestation, intervieweradministered questionnaires were conducted to obtain maternal demographic characteristics. Maternal early pregnancy weight was based on body weight measured at first antenatal clinic visit during the first trimester ( $\leq 14$ weeks of gestation). Maternal height was measured with a SECA 213 stadiometer (SECA). Maternal early pregnancy ( $\leq 14$ weeks of gestation) BMI was calculated as weight $(\mathrm{kg}) /$ height $^{2}(\mathrm{~m})$, and classified as underweight $\left(\mathrm{BMI}<18.5 \mathrm{~kg} / \mathrm{m}^{2}\right)$, normal $\left(\mathrm{BMI}=18.5-22.9 \mathrm{~kg} / \mathrm{m}^{2}\right)$ and at risk of overweight/overweight (BMI $\geq 23.0 \mathrm{~kg} / \mathrm{m}^{2}$ ) according to WHO BMI classification for Asian countries ${ }^{(25)}$.

\section{Infant characteristics}

Infant sex, gestational age and birth order were extracted from medical records. Infant feeding modes during the first 6 months of life were ascertained through interviewer-administered questionnaires with mothers at 3 and 6 months. Based on the WHO definition ${ }^{(26)}$, infant feeding modes were classified as follows: (1) exclusive breast-feeding, in which the infant received only breast milk and no other liquids or solids except drops or syrups including vitamins, mineral supplements or medicines; (2) predominant breast-feeding, in which the infant received primarily breast milk and some water-based drinks; (3) partial breast-feeding, in which the infant received a combination of breast milk and formula milk; and (4) formula-feeding, in which the infant received only formula milk. We further reclassified infants into the following groups: the exclusively/predominantly breast-fed group which includes infants fed via methods 1 and/or 2 
for the entire first 6 months of life; the mixed-fed group which includes infants who fed via method 3 only or methods 1 and/or 2 with 3 and/or 4 or methods 3 and 4 in the first 6 months; and the exclusively formula-fed group which includes infants fed via method 4 for the entire first 6 months of life ${ }^{(27)}$. Milk feeding mode at 12 months was also recorded through interviewer-administered questionnaires with mothers.

Infant anthropometric measurements were performed by trained clinical staff within 24-h of birth and at 12 months, using standardised techniques ${ }^{(28)}$. Weight was recorded to the nearest $0.001 \mathrm{~kg}$ using SECA 334 baby weighing scale (SECA). Recumbent crown-heel length was measured to the nearest $0 \cdot 1 \mathrm{~cm}$ using SECA 210 Mobile Measuring Mat (SECA). Based on the WHO Child Growth Standards 2006, infant anthropometric measurements were converted into weight-for-length $z$ score (WLZ) using WHO Anthro software (version 3.2.2). Growth changes from birth to 12 months were calculated as differences in WLZ from birth to 12 months. Using the validated Brief Infant Sleep Questionnaire ${ }^{(29)}$, mothers were asked to refer to their infant's sleeping habits for the last 1 week and record his/her day and night sleep durations in hours and minutes, and usual bedtime in 24-h clock format. Infant total sleep duration was calculated as the sum of day and night sleep durations.

\section{Infant dietary assessment}

Infant dietary intakes were assessed at 12 months. A 24-h dietary recall was administered to mothers by trained clinical staff with the use of the five-stage, multiple-pass interviewing technique ${ }^{(30)}$ to record food and beverage intakes, together with feeding times, consumed by their child on the previous day. Mothers were asked whether the assessed infant food intakes were typical or atypical compared with other unrecorded days. Total daily energy and nutrient analyses of the dietary recalls were performed with nutrient analysis software (Dietplan version 7; Forestfield Software) that had food composition database of locally available food ${ }^{(31)}$. For mixed dishes not found in the database, nutrient analyses of recipes were performed by the software. For other food items not found in the database, nutrient information was obtained from either food labels or the USDA national nutrient database ${ }^{(32)}$. Proportions of macronutrient intake were expressed as percentage of total energy intake and calculated as the amount of energy intake from macronutrient $(\mathrm{kJ}(\mathrm{kcal})) /$ total energy intake $(\mathrm{kJ}(\mathrm{kcal})) \times 100 \%$.

\section{Infant circadian feeding patterns}

The mean hourly energy intake and proportion of infants fed against time were graphically depicted (Fig. 1). Both variables were relatively low from 00.00-05.59 hours. This timeframe, termed post-midnight, was henceforth identified to be a period of less common feeding hours. Based on whether they were fed during the post-midnight period or not, infants were classified into post-midnight (00.00-05.59 hours) and pre-midnight (06.00-23.59 hours) feeders, respectively.

\section{Statistical analyses}

Descriptive analysis was performed to determine the mean daily energy and macronutrient intakes. Differences between pre-midnight and post-midnight feeders were compared using Fisher's exact test for categorical variables and independent sample $t$ test for continuous variables. The association of maternal and infant characteristics with feeding patterns was tested using multivariable logistic regression. All maternal and infant characteristics were entered simultaneously in the model. The analysis was repeated in a separate model that included a subsample of infants whose total sleep duration was reported ( $n$ 171). Lastly, a sensitivity analysis of the main model was performed using data from infants whose feeding patterns were reported as typical, which could better reflect the usual dietary intakes of the infants. All $P$ values were two-tailed, with $P<0.05$ considered to be statistically significant. All statistical analyses were performed using Statistical Package for the Social Sciences, version 19.0 (SPSS Inc.).

\section{Results}

\section{Participant characteristics}

Among 1237 recruited participants, a total of 431 infants with complete 24-h dietary recalls were included in this study. Maternal and infant characteristics were similar between excluded and included participants except for ethnicity, monthly household income, birth order and feeding mode in the first 6 months of life (all $P<0.05$ ) (online Supplementary Table S1). Table 1 shows the maternal and infant characteristics of the included participants. Table 2 shows the mean daily $24-\mathrm{h}$ dietary intakes of infants.

\section{4-h energy intake profile}

A graph of mean hourly energy intake and proportion of infants fed against time was plotted (Fig. 1). The mean energy intake at 06.00 hours was 117 (SD 264) kJ (28 (SD 63) kcal). Thereafter, it increased and fluctuated between approximately 134-192 kJ (32-46 kcal) from 07.00-20.59 hours. At 21.00 hours, the mean energy intake peaked at 259 (sD 423) kJ (62 (sD 101) kcal), just before the mean bedtime at 22.01 hours. It decreased sharply towards a nadir at 00.00 hours and remained below $84 \mathrm{~kJ}(20 \mathrm{kcal})$ from 01.00-05.59 hours. The hourly proportion of infants fed showed a similar trend. At 06.00 hours, $21.3 \%$ of infants were fed. Thereafter, it increased to $28 \%$ at 07.00 hours and fluctuated between approximately 33-46\% from 08.00-21.59 hours before decreasing substantially to approximately $26 \%$ at 22.00 and 23.00 hours. At 00.00 hours, the proportion of infants fed was the lowest at $2 \cdot 3 \%$. It remained below $10 \%$ from 01.00 to 05.59 hours, with the exception of 03.00 hours when $12.1 \%$ of infants were fed.

We observed that both mean hourly energy intake and proportion of infants fed were relatively low during 00.0005.59 hours. Both variables increased substantially at 06.00 hours and remained in the higher range from 06.00-23.59 hours. As such, two distinct feeding patterns could be observed using 06.00 hours as the cut-off time. The first category includes infants who had at least one feed between 00.00 and 05.59 hours (post-midnight feeders), whereas the second includes infants who fed solely from 06.00 to 23.59 hours (pre-midnight feeders). Analysis revealed that 180 infants (41.8\%) had at least one 
Table 1. Maternal and infant characteristics ( $n$ 431)

(Numbers and percentages for categorical variables; mean values and standard deviations for continuous variables)

\begin{tabular}{|c|c|c|c|c|c|c|c|}
\hline \multirow[b]{2}{*}{ Characteristics } & \multicolumn{2}{|c|}{ Overall (n 431) } & \multicolumn{2}{|c|}{ Pre-midnight feeders ( $n$ 251) } & \multicolumn{2}{|c|}{ Post-midnight feeders ( $n$ 180) } & \multirow[b]{2}{*}{$P^{*}$} \\
\hline & Mean $/ n$ & $\mathrm{sD} / \%$ & Mean $/ n$ & $\mathrm{SD} / \%$ & Mean $/ n$ & $\mathrm{SD} / \%$ & \\
\hline \multicolumn{8}{|l|}{ Maternal } \\
\hline Ethnicity & & & & & & & 0.055 \\
\hline Chinese & 223 & $51 \cdot 7$ & 142 & $56 \cdot 6$ & 81 & $45 \cdot 0$ & \\
\hline Malay & 100 & $23 \cdot 2$ & 51 & $20 \cdot 3$ & 49 & $27 \cdot 2$ & \\
\hline Indian & 108 & $25 \cdot 1$ & 58 & $23 \cdot 1$ & 50 & $27 \cdot 8$ & \\
\hline Educational level & & & & & & & 0.007 \\
\hline Secondary and lower & 144 & $34 \cdot 0$ & 71 & $28 \cdot 7$ & 73 & 41.5 & \\
\hline Post-secondary and higher & 279 & $66 \cdot 0$ & 176 & $71 \cdot 3$ & 103 & 58.5 & \\
\hline Monthly household income (SGD) & & & & & & & 0.002 \\
\hline 0-1999 & 77 & $19 \cdot 0$ & 38 & $16 \cdot 3$ & 39 & $22 \cdot 5$ & \\
\hline $2000-5999$ & 229 & $56 \cdot 4$ & 123 & $52 \cdot 8$ & 106 & $61 \cdot 3$ & \\
\hline$\geq 6000$ & 100 & $24 \cdot 6$ & 72 & $30 \cdot 9$ & 28 & $16 \cdot 2$ & \\
\hline Early pregnancy BMI $\left(\mathrm{kg} / \mathrm{m}^{2}\right)$ & & & & & & & 0.180 \\
\hline Underweight $(<18.5)$ & 35 & $8 \cdot 4$ & 23 & $9 \cdot 5$ & 12 & 6.9 & \\
\hline Normal (18.5-22.9) & 176 & $42 \cdot 4$ & 110 & $45 \cdot 3$ & 68 & $38 \cdot 9$ & \\
\hline At risk for overweight/overweight $(\geq 23.0)$ & 204 & $49 \cdot 2$ & 110 & $45 \cdot 3$ & 95 & $54 \cdot 3$ & \\
\hline Age (years) & $30 \cdot 42$ & $5 \cdot 23$ & $30 \cdot 41$ & $5 \cdot 21$ & $30 \cdot 44$ & $5 \cdot 27$ & 0.949 \\
\hline \multicolumn{8}{|l|}{ Infant } \\
\hline Sex & & & & & & & 0.064 \\
\hline Male & 226 & $52 \cdot 4$ & 122 & $48 \cdot 6$ & 104 & $57 \cdot 8$ & \\
\hline Female & 205 & $47 \cdot 6$ & 129 & 51.4 & 76 & $42 \cdot 2$ & \\
\hline Gestational age (weeks) & & & & & & & 1.000 \\
\hline$<37$ & 30 & $7 \cdot 0$ & 18 & $7 \cdot 2$ & 12 & $6 \cdot 7$ & \\
\hline$\geq 37$ & 401 & $93 \cdot 0$ & 233 & $92 \cdot 8$ & 168 & $93 \cdot 3$ & \\
\hline Birth order & & & & & & & 0.234 \\
\hline First child & 175 & $40 \cdot 6$ & 108 & $43 \cdot 0$ & 67 & $37 \cdot 2$ & \\
\hline Not first child & 256 & $59 \cdot 4$ & 143 & $57 \cdot 0$ & 113 & $62 \cdot 8$ & \\
\hline Feeding mode in the first 6 months of life & & & & & & & 0.003 \\
\hline Exclusively formula-fed & 118 & $29 \cdot 6$ & 61 & $26 \cdot 1$ & 57 & $34 \cdot 5$ & \\
\hline Mixed-fed & 242 & $60 \cdot 7$ & 141 & $60 \cdot 3$ & 101 & $61 \cdot 2$ & \\
\hline Exclusively/predominantly breast-fed & 39 & $9 \cdot 8$ & 32 & $13 \cdot 7$ & 7 & $4 \cdot 2$ & \\
\hline Milk feeding mode at 12 months & & & & & & & 0.003 \\
\hline Exclusively formula-fed & 357 & $85 \cdot 6$ & 196 & $81 \cdot 0$ & 161 & $92 \cdot 0$ & \\
\hline Mixed-fed & 56 & $13 \cdot 4$ & 42 & $17 \cdot 4$ & 14 & 8.0 & \\
\hline Exclusively/predominantly breast-fed & 4 & 1.0 & 4 & 1.7 & 0 & 0.0 & \\
\hline WLZ change ( $z$ score) & -0.05 & 1.48 & -0.01 & 1.47 & -0.15 & 1.48 & 0.267 \\
\hline \multicolumn{8}{|l|}{ Sleep duration $(\mathrm{h}) \dagger$} \\
\hline Total & 11.63 & 1.83 & 11.77 & 1.77 & $11 \cdot 42$ & 1.91 & 0.225 \\
\hline Day & $2 \cdot 63$ & 1.33 & 2.59 & $1 \cdot 22$ & $2 \cdot 70$ & 1.49 & 0.596 \\
\hline Night & 9.00 & 1.36 & $9 \cdot 18$ & $1 \cdot 24$ & $8 \cdot 72$ & 1.52 & 0.041 \\
\hline Bedtime (h) $\ddagger$ & 22.01 & 01.07 & 22.09 & 01.05 & 21.49 & 01.10 & 0.058 \\
\hline 24-h dietary recall & & & & & & & 1.000 \\
\hline Atypical & 64 & $14 \cdot 8$ & 38 & $16 \cdot 2$ & 26 & $15 \cdot 7$ & \\
\hline Typical & 337 & $78 \cdot 2$ & 197 & $83 \cdot 8$ & 140 & $84 \cdot 3$ & \\
\hline
\end{tabular}

SGD, Singapore dollar; WLZ, weight-for-length $z$ score.

${ }^{*} P$ values are based on Fisher's exact test or independent $t$ test as appropriate.

† Based on a subsample of 171 infants (105 pre-midnight feeders and sixty-six post-midnight feeders).

‡ Based on a subsample of 170 infants (104 pre-midnight feeders and sixty-six post-midnight feeders).

post-midnight feed, whereas the remaining 251 infants (58.2\%)

only received feeds during the pre-midnight hours.

\section{Comparison of feeding patterns}

Table 1 shows the comparison of maternal and infant characteristics between pre-midnight and post-midnight feeders. Compared with pre-midnight feeders, post-midnight feeders were more likely to be born to mothers who had lower education attainment $(P=0.007)$ and lower monthly household income $(P=0.002)$. Post-midnight feeders were also more likely to be partially breast-fed and exclusively formula-fed in the first 6 months of life ( $P=0.003)$, received only formula milk as their source of milk at
12 months $(P=0.003)$ and had shorter night sleep duration $(P=0 \cdot 041)$. No significant differences in other characteristics were observed between pre-midnight and post-midnight feeders.

Table 2 shows the comparison of dietary intakes between pre-midnight and post-midnight feeders. Post-midnight feeders consumed higher energy, carbohydrate, fat and protein intakes compared with pre-midnight feeders (all $P<0 \cdot 001$ ). Proportions of carbohydrate, fat and protein were not significantly different between the two groups (all $P>0 \cdot 05$ ). A further comparison of dietary intakes during the pre-midnight hours was performed. During this period, energy and macronutrient intakes were not significantly different between pre-midnight and post-midnight feeders (all $P \geq 0 \cdot 05$ ). 
Table 2. 24-h dietary intakes of infants ( $n$ 431)

(Numbers and percentages for categorical variables; mean values and standard deviations for continuous variables)

\begin{tabular}{|c|c|c|c|c|c|c|c|}
\hline & \multicolumn{2}{|c|}{ Overall ( $n$ 431) } & \multicolumn{2}{|c|}{ Pre-midnight feeders ( $n$ 251) } & \multicolumn{2}{|c|}{ Post-midnight feeders ( $n$ 180) } & \multirow[b]{2}{*}{$P^{*}$} \\
\hline & Mean & SD & Mean & SD & Mean & SD & \\
\hline \multicolumn{8}{|l|}{ 00.00-23.59 hours } \\
\hline Energy (kJ) & 3234 & 950 & 3017 & 795 & 3531 & 1071 & $<0.001$ \\
\hline Energy (kcal) & 773 & 227 & 721 & 190 & 844 & 256 & $<0.001$ \\
\hline Carbohydrate (g) & $100 \cdot 20$ & 34.96 & 93.56 & 29.84 & $109 \cdot 46$ & $39 \cdot 30$ & $<0.001$ \\
\hline Fat $(\mathrm{g})$ & $29 \cdot 10$ & $10 \cdot 16$ & $27 \cdot 20$ & $9 \cdot 18$ & 31.74 & $10 \cdot 87$ & $<0.001$ \\
\hline Protein $(g)$ & $27 \cdot 69$ & 9.66 & $25 \cdot 83$ & $8 \cdot 20$ & $30 \cdot 29$ & $10 \cdot 90$ & $<0.001$ \\
\hline \multicolumn{8}{|l|}{ Proportion (\% energy) } \\
\hline Carbohydrate & $51 \cdot 8$ & $7 \cdot 8$ & $52 \cdot 0$ & $7 \cdot 8$ & $51 \cdot 7$ & $7 \cdot 7$ & 0.704 \\
\hline Fat & 33.9 & $7 \cdot 2$ & 33.8 & $7 \cdot 6$ & 34.0 & $6 \cdot 6$ & 0.842 \\
\hline Protein & 14.4 & $3 \cdot 2$ & 14.4 & 3.2 & 14.4 & 3.3 & 0.971 \\
\hline \multicolumn{8}{|l|}{ 06.00-23.59 hours } \\
\hline Energy (kJ) & - & - & 3017 & 795 & 2920 & 946 & 0.241 \\
\hline Energy (kcal) & - & - & 721 & 190 & 698 & 226 & 0.241 \\
\hline Carbohydrate (g) & - & - & 93.56 & $29 \cdot 84$ & 91.52 & $34 \cdot 27$ & 0.512 \\
\hline Fat $(\mathrm{g})$ & - & - & $27 \cdot 20$ & $9 \cdot 18$ & $25 \cdot 38$ & 9.98 & 0.051 \\
\hline Protein $(\mathrm{g})$ & - & - & $25 \cdot 83$ & $8 \cdot 20$ & $25 \cdot 83$ & $10 \cdot 17$ & 1.000 \\
\hline Proportion (\% energy) & - & - & & & & & \\
\hline Carbohydrate & - & - & $52 \cdot 0$ & $7 \cdot 8$ & $52 \cdot 5$ & 8.5 & 0.493 \\
\hline Fat & - & - & 33.8 & 7.6 & $32 \cdot 6$ & $7 \cdot 3$ & 0.099 \\
\hline Protein & - & - & 14.4 & $3 \cdot 2$ & $15 \cdot 0$ & 3.8 & 0.118 \\
\hline
\end{tabular}

${ }^{*} P$ values are based on Fisher's exact test or independent $t$ test as appropriate.

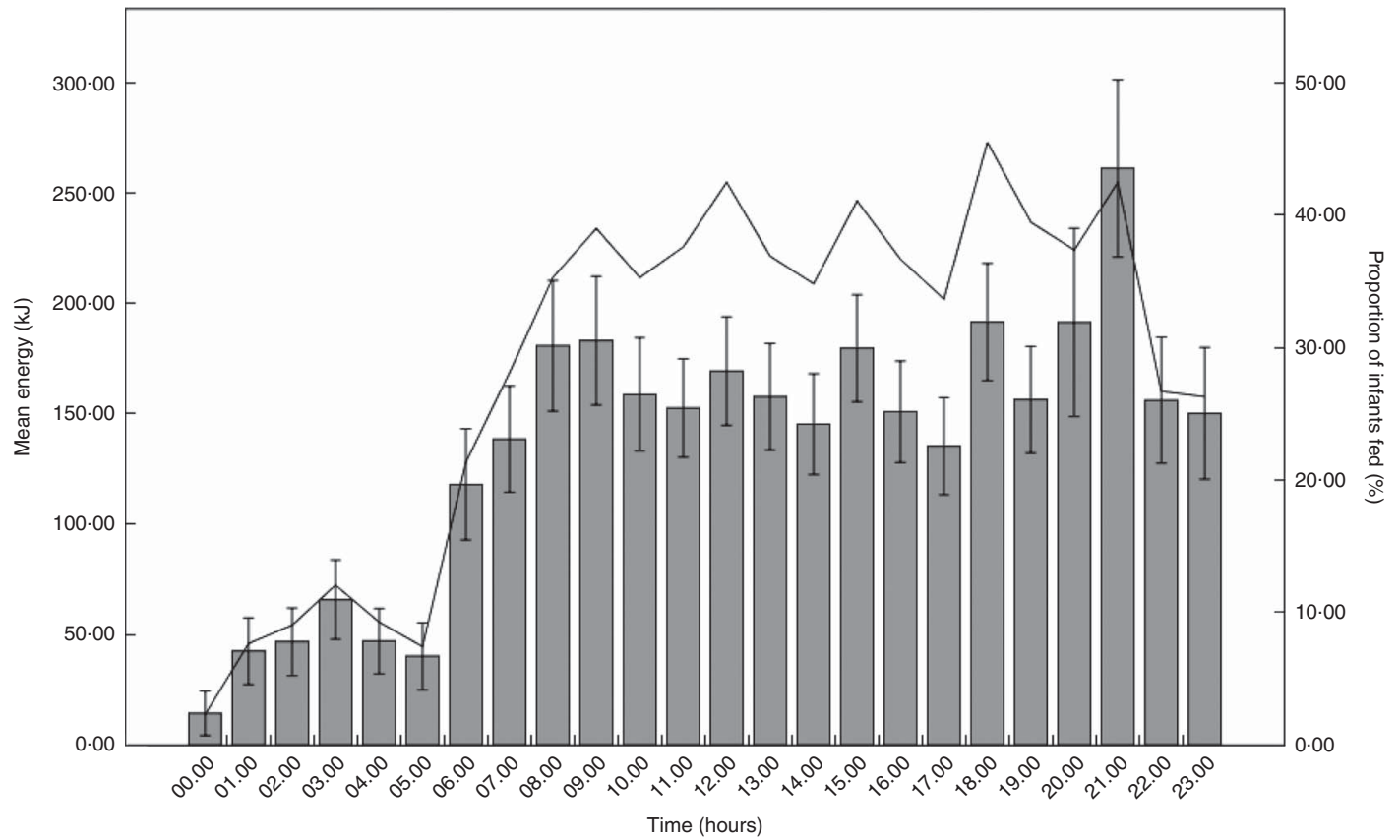

Fig. 1. Mean hourly energy intake and proportion of infants fed across $24 \mathrm{~h}$. Values are means and proportions and $95 \% \mathrm{Cl}$ represented by vertical bars. $\square$, Mean energy intake; - , proportion of infants fed.

\section{Post-midnight dietary intakes}

Table 3 shows the dietary intakes during the post-midnight hours. The mean energy intake was 615 (SD 301) kJ (147 (SD 72) kcal) which constituted 17.6 ( $\mathrm{SD} 7.5$ ) \% of the mean daily energy intake. On average, carbohydrate, fat and protein comprised 48.9 (SD 8.4), 38.8 (SD 8.0 ) and 12.4 (SD 2.0)\% of post-midnight energy intake, respectively. A total of $173(96 \cdot 1 \%)$ post-midnight feeders consumed formula milk, 10 (5.6\%) consumed whole milk and solid food, 7 (3.9\%) consumed breast milk during post-midnight hours.

\section{Association of circadian feeding patterns with maternal and infant characteristics}

Table 4 shows the crude and adjusted OR for post-midnight feeding according to maternal and infant characteristics. 
Compared with pre-midnight feeders, post-midnight feeders were more likely to be Malay (OR 1.68; $95 \%$ CI 1.05, 2.72; $P=0.032$ ), less likely to be born to mothers who had higher educational levels (OR 0.57; $95 \%$ CI 0.38, 0.86; $P=0.007$ ) and higher monthly household income (OR 0.38; $95 \%$ CI 0.20, 0.71;

Table 3. Post-midnight dietary intakes of post-midnight feeders $(n 180)$ (Numbers and percentages for categorical variables; mean values and standard deviations for continuous variables)

\begin{tabular}{lcc}
\hline & Mean $/ n$ & $\mathrm{sD} / \%$ \\
\hline Energy (kJ) & 615 & 301 \\
Energy (kcal) & 147 & 72 \\
Carbohydrate (g) & 17.94 & $9 \cdot 31$ \\
Fat (g) & $6 \cdot 36$ & 3.82 \\
Protein (g) & 4.45 & 2.05 \\
Proportion (\% energy) & & \\
$\quad$ Carbohydrate & 48.9 & 8.4 \\
Fat & 38.8 & 8.0 \\
Protein & 12.4 & $2 \cdot 0$ \\
Food consumed & & \\
$\quad$ Breast milk & 7 & 3.9 \\
$\quad$ Formula milk & 173 & 96.1 \\
Others & 10 & 5.6 \\
\hline
\end{tabular}

$P=0.002$ ), and they were also less likely to be exclusively breast-fed in the first 6 months of life (OR 0.23; 95\% CI 0.10, $0.57 ; P=0.001)$. In the mutually adjusted model, only exclusively breast-feeding during the first 6 months of life remained significantly associated with post-midnight feeding at 12 months (OR $0.31 ; 95 \%$ CI $0.11,0.82 ; P=0.019$ ). The analysis was repeated in a submodel with an additional confounder adjustment of infant total sleep duration at 12 months ( $n$ 171) (Table not shown). No association was found between post-midnight feeding and total sleep duration (OR 0.90; $95 \%$ CI 0.73 1.12; $P=0.356$ ). However, the association between exclusively breast-feeding during the first 6 months of life and postmidnight feeding remained significant after additional adjustment for infant total sleep duration at 12 months (OR 0.20; $95 \%$ $\mathrm{CI}=0.04,0.97 ; P=0.046$ ). The sensitivity analysis performed on infants whose 24-h dietary recalls were reported as typical presented similar findings (online Supplementary Table S2).

\section{Discussion}

This study describes the circadian feeding patterns of 12-monthold infants in an Asian multi-ethnic cohort, in terms of both

Table 4. Association of maternal and infant characteristics with post-midnight feeding (Odds ratios and $95 \%$ confidence intervals)

\begin{tabular}{|c|c|c|c|c|c|c|}
\hline & \multicolumn{6}{|c|}{ Post-midnight feeding } \\
\hline & \multicolumn{3}{|c|}{ Crude } & \multicolumn{3}{|c|}{ Adjusted ${ }^{*}$} \\
\hline & OR & $95 \% \mathrm{Cl}$ & $P$ & OR & $95 \% \mathrm{Cl}$ & $P$ \\
\hline \multicolumn{7}{|l|}{ Maternal } \\
\hline \multicolumn{7}{|l|}{ Ethnicity } \\
\hline Chinese & \multicolumn{3}{|c|}{ Ref. } & \multicolumn{2}{|c|}{ Ref. } & \\
\hline Malay & 1.68 & $1 \cdot 05,2 \cdot 72$ & 0.032 & 1.26 & $0.70,2 \cdot 28$ & 0.437 \\
\hline Indian & 1.51 & $0.95,2.41$ & 0.083 & 1.33 & $0.74,2.39$ & 0.347 \\
\hline \multicolumn{7}{|l|}{ Educational level } \\
\hline Secondary or lower & \multicolumn{2}{|c|}{ Ref. } & \multicolumn{4}{|c|}{ Ref. } \\
\hline Post-secondary or above & 0.57 & $0.38,0.86$ & 0.007 & 1.06 & $0.62,1.81$ & 0.844 \\
\hline \multicolumn{7}{|l|}{ Monthly household income (SGD) } \\
\hline $0-1999$ & \multicolumn{2}{|c|}{ Ref. } & \multicolumn{4}{|c|}{ Ref. } \\
\hline 2000-5999 & 0.84 & $0.50,1.41$ & 0.508 & 0.84 & $0.45,1.56$ & 0.578 \\
\hline$\geq 6000$ & 0.38 & $0.20,0.71$ & 0.002 & 0.48 & $0.21,1.09$ & 0.079 \\
\hline \multicolumn{7}{|l|}{ Early pregnancy BMI $\left(\mathrm{kg} / \mathrm{m}^{2}\right)$} \\
\hline Underweight $(<18.5)$ & \multicolumn{2}{|c|}{ Ref. } & \multicolumn{4}{|c|}{ Ref. } \\
\hline Normal (18.5-22.9) & $1 \cdot 19$ & $0.55,2.54$ & 0.662 & 1.29 & $0.52,3.15$ & 0.583 \\
\hline At risk for overweight/overweight $(\geq 23.0)$ & 1.66 & $0.782,3.50$ & 0.188 & 1.58 & $0.63,3.93$ & 0.329 \\
\hline Maternal age (years) & 1.00 & $0.97,1.04$ & 0.949 & 1.03 & $0.99,1.09$ & 0.173 \\
\hline \multicolumn{7}{|l|}{ Infant } \\
\hline \multicolumn{7}{|l|}{ Sex } \\
\hline Male & \multicolumn{2}{|c|}{ Ref. } & \multicolumn{4}{|c|}{ Ref. } \\
\hline Female & 0.69 & $0.47,1.02$ & 0.060 & 0.71 & $0.45,1.11$ & 0.133 \\
\hline \multicolumn{7}{|l|}{ Gestational age (weeks) } \\
\hline$<37$ & \multicolumn{2}{|c|}{ Ref. } & \multicolumn{4}{|c|}{ Ref. } \\
\hline$\geq 37$ & 1.08 & $0.51,2.31$ & 0.839 & 0.99 & $0.34,2.86$ & 0.988 \\
\hline \multicolumn{7}{|l|}{ Birth order } \\
\hline First child & \multicolumn{2}{|c|}{ Ref. } & \multicolumn{4}{|c|}{ Ref. } \\
\hline Not first child & 1.27 & $0.86,1.89$ & 0.226 & $1 \cdot 12$ & $0.69,1.82$ & 0.656 \\
\hline \multicolumn{7}{|l|}{ Feeding modes in the first 6 months of life } \\
\hline Exclusively formula-fed & \multicolumn{2}{|c|}{ Ref. } & & & ef. & \\
\hline Mixed-fed & 0.77 & $0.49,1.19$ & 0.239 & 0.72 & $0.42,1.21$ & 0.209 \\
\hline Exclusively/predominantly breast-fed & 0.23 & $0.10,0.57$ & 0.001 & 0.31 & $0.11,0.82$ & 0.019 \\
\hline WLZ change ( $z$ score) & 0.93 & $0.81,1.06$ & 0.266 & 1.01 & $0.86,1.18$ & 0.923 \\
\hline
\end{tabular}

Ref., referent values; SGD, Singapore dollar; WLZ, weight-for-length $z$ score.

* Mutually adjusted model (i.e. adjusted for all other maternal and infants characteristics). 
energy intake and macronutrient proportions. These infants consumed an average daily energy intake of $3234 \mathrm{~kJ}(773 \mathrm{kcal})$, mainly from carbohydrates, followed by fat and protein. We identified two circadian feeding patterns, namely pre-midnight and post-midnight feeding. Post-midnight feeding was highly prevalent at $41 \cdot 8 \%$. These infants had higher daily energy and macronutrient intakes compared with pre-midnight feeders, even though their pre-midnight energy and macronutrient intakes were not significantly different. Altogether, our findings suggest that feeding after midnight affects daily energy and macronutrient intakes during infancy.

Inappropriate timing of food consumption may lead to circadian misalignment. Adult studies have shown that shift work ${ }^{(33,34)}$ breakfast skipping ${ }^{(20,23)}$ and nocturnal eating ${ }^{(18,35)}$ adversely affect glucose metabolism and enhance the risk of metabolic diseases, implying that circadian misalignment may impair metabolic pathways. Similar evidence is also presented in limited adolescent and children studies ${ }^{(21,22,36)}$. Although these studies investigated specific eating behaviours, it may be more holistic to consider the temporal pattern of energy intake throughout the day. In this study, we classified infants by considering the pattern of mean energy intake and proportion of infants fed over $24 \mathrm{~h}$. This model provided us with new insights into the circadian feeding pattern of 12-month-old infants.

First, post-midnight feeding was highly prevalent among infants. This warrants attention as post-midnight feeding may be non-physiological. The human body is well-adapted to tolerate hours of fasting, including overnight fasting. Our circadian clock shares intimate and reciprocal relationships with central metabolic pathways; peripheral oscillators in different organs modulate daily rhythms in the transcription and translation of genes that tightly control cellular metabolism, repair, cell division and growth ${ }^{(37)}$. The temporal synchronisation of these processes with the central circadian clock enhances fitness, confers robustness and ensures stability to the overall temporal structure of the body ${ }^{(37,38)}$. On the other hand, frequent energy intake and the absence of a definite fasting period may prolong fed-state physiology and disrupt normal counter-regulatory metabolic processes that occur during fasting ${ }^{(38)}$. Energy intake activates the insulin-pAKT-mammalian target of rapamycin (mTOR) pathway which regulates anabolic processes, whereas fasting activates AMPK which promotes catabolism ${ }^{(38)}$. The mTOR signalling pathway is known to contribute to adipose tissue expansion and insulin resistance ${ }^{(39)}$. Aligning feeding/fasting cycles to the circadian clock allows energy regulation signalling pathways to become physiologically quiescent during the night. Inappropriate timing of energy intake, for example during post-midnight, prevents this from occurring. Both animal and human studies have demonstrated the consequences of circadian misalignment. Mice fed inappropriately during the light phase exhibited significantly higher body mass and reduced glucose tolerance compared those fed during the dark phase, despite similar total energy intakes and motor activity ${ }^{(16,17)}$. Adults who consumed higher energy intake in the evening were more likely to be overweight or obese ${ }^{(40)}$, whereas participants from a weight loss study provided with high-energy breakfast experienced greater weight loss and waist circumference reduction than those on an isoenergetic diet with high energy intake at dinner ${ }^{(41)}$.
Second, post-midnight feeders consumed higher daily energy and macronutrient intakes than pre-midnight feeders across $24 \mathrm{~h}$, with the additional intake originating from post-midnight feed(s). A carefully controlled inpatient study that observed healthy adult participants' ad libitum nighttime food intake ${ }^{(42)}$ produced comparable findings; those who ate during nighttime (23.00-05.00 hours) consumed significantly higher daily energy and macronutrient intakes than non-nighttime eaters ${ }^{(42)}$. Both groups consumed similar energy intake during non-nighttime, indicating that the difference in daily energy intake resulted from energy content ingested during nighttime ${ }^{(42)}$. Studies have demonstrated the associations of higher energy intake with adverse metabolic outcomes. In the aforementioned study, nighttime eaters gained significantly more weight than nonnighttime eaters during the follow-up period despite having similar BMI or percentage body fat at baseline ${ }^{(42)}$. The Avon Longitudinal Study of Parents and Children birth cohort also reported that higher energy intake at 4 months was positively associated with early childhood weight gain and subsequent body weight and BMI up to 5 years of age, although this finding was limited to formula- or mixed-fed infants ${ }^{(15)}$. These findings, if applicable to this study, suggest that post-midnight feeding during infancy may be metabolically disadvantageous. Further studies are needed to determine if higher daily energy intake due to post-midnight feed(s) during early life is associated with metabolic disorders.

Third, post-midnight energy intake came mainly from formula milk. The practice of formula-feeding during the night appears to be prevalent among children of similar age range in other countries. In the Gemini twin cohort study, over $90 \%$ of energy intake during the night were from milk drinks consumed before midnight ${ }^{(43)}$. In Sri Lanka, 82.6\% of children aged between 24 and 60 months received night feeding in the form of formula milk or a mixed feeding ${ }^{(44)}$. The slight differences in proportion from our study might be attributed to cultural and economic differences, as well as differences in the timeframe studied.

Lastly, our findings also suggest that feeding mode during the first 6 months of life is associated with the circadian feeding pattern of infants at 12 months. Compared with exclusively breastfed infants during the first 6 months of life, infants who received only formula milk during the first 6 months of life were more likely to be a post-midnight feeder at 12 months. Together with the earlier finding that post-midnight energy intake came mainly from formula milk, this suggests that the practice of formula-feeding during postmidnight hours might have continued beyond early infancy in exclusively formula-fed infants. We speculate that routinely formula-feeding, in response to night awakening or perceived hunger, during post-midnight hours has become habitual in these caregivers who might not have taken the infant's physiological needs into consideration. We also noticed a surge in the mean energy intake from 21.00 to 22.00 hours, just before the mean bedtime at 22.01 hours. Energy consumption, usually in the form of formula milk, is a common strategy adopted by caregivers to promote sleep among infants and young children during the night. However, as observed in our study, post-midnight feeds may increase the daily energy intake beyond the sufficient requirement of the infant ${ }^{(45)}$.

The strengths of this study include a large sample size, its prospective study design and standardised anthropometric 
measurements of mothers and infants by trained research personnel. Moreover, as Singapore lies near the equator with fairly constant light/dark cycles, our findings were less likely to be affected by seasonal changes which might otherwise influence the circadian pattern of energy intake ${ }^{(46,47)}$. However, this study does have limitations. First, there were differences in maternal and infant characteristics between excluded and included study participants but these characteristics have been adjusted for in the multivariable logistic analyses. Second, the use of self-reported 24-h dietary recall might not reflect habitual consumption patterns. Daily variation of feeding times could have led to misclassification of infants according to temporal feeding patterns. However, close to $80 \%$ of the recalls were reported to be typical of the infant's feeding routine. Our findings from the sensitivity analysis using these recalls were found to be similar to those in the main analysis. Third, our analyses using sleep data was limited as the sample size with this data was small. Nevertheless, the addition of total sleep duration as covariate did not affect our findings. Lastly, we did not further assess parental feeding practices and beliefs to understand the reasons behind the circadian feeding patterns, and hence could not make a conclusion on whether post-midnight feeding is driven by infant biological and/or parental behaviour.

In conclusion, this study provides new insights into the temporal feeding pattern of 12-month-old infants and identifies two prevailing feeding patterns - pre-midnight and post-midnight feeding. Post-midnight feeds, with formula milk making up the majority, contributed to higher daily energy and macronutrient intakes. Our findings also suggest that feeding mode during early infancy is associated with subsequent feeding pattern. However, more studies are needed to replicate these findings and to understand their biological mechanisms, particularly among infants at high-risk of nutritional deficiencies. Also, long-term studies are warranted to confirm about the implications of post-midnight feeding on subsequent growth and development of children as it is currently unknown whether post-midnight feeding is physiological or otherwise. Importantly, our study raises the possibility of including advice on appropriate feeding times when considering daily energy intake in infancy. We recommend more attention to be given to circadian feeding patterns during early life.

\section{Acknowledgements}

The authors thank the study subjects and their families for their participation. The authors also acknowledge the GUSTO study group, which includes Pratibha Agarwal, Arijit Biswas, Choon Looi Bong, Birit F. P. Broekman, Shirong Cai, Yiong Huak Chan, Cornelia Yin Ing Chee, Helen Chen, Amutha Chinnadurai, Chai Kiat Chng, Shang Chee Chong, Mei Chien Chua, Doris Fok, Marielle V. Fortier, Anne Eng Neo Goh, Yam Thiam Daniel Goh, Joshua J. Gooley, Wee Meng Han, Mark Hanson, Christiani Jeyakumar Henry, Joanna D. Holbrook, Chin-Ying Hsu, Neerja Karnani, Jeevesh Kapur, Ivy Yee-Man Lau, Bee Wah Lee, Yung Seng Lee, Sok Bee Lim, Iliana Magiati, Lourdes Mary Daniel, Michael Meaney, Cheryl Ngo, Krishnamoorthy Niduvaje, Wei Wei Pang, Anqi Qiu, Boon Long Quah, Victor Samuel Rajadurai, Mary Rauff, Salome A. Rebello, Jenny L. Richmond, Anne Rifkin-Graboi, Lynette Pei-Chi Shek, Allan Sheppard, Borys Shuter, Leher Singh,
Shu-E. Soh, Walter Stunkel, Lin Lin Su, Kok Hian Tan, Oon Hoe Teoh, Mya Thway Tint, Hugo P. S. van Bever, Rob M. van Dam, Inez Bik Yun Wong, P. C. Wong and George Seow Heong Yeo.

This study was supported by the Singapore National Research Foundation under its Translational and Clinical Research Flagship Programme and administered by the Singapore Ministry of Health's National Medical Research Council, Singapore-NMRC/TCR/004-NUS/2008; NMRC/TCR/ 012-NUHS/2014. Additional funding was provided by the Singapore Institute for Clinical Sciences, Agency for Science Technology and Research (A*STAR), Singapore. K. M. G. is supported by the National Institute for Health Research through the NIHR Southampton Biomedical Research Centre and by the European Union's Seventh Framework Programme (FP7/20072013), project EarlyNutrition under grant agreement no. 289346. J. K. Y. C. received salary support from the Ministry of Health's National Medical Research Council, Singapore (NMRC/CSA/ 043/2012).

K. M. G., P. D. G., S. M. S. and Y.-S. C. designed the GUSTO cohort study. P. H. W., S. L. L. and F. Y. designed the present study. P. H. W., S. L. L., J. Y. T., E. K. H. T. and D. Y. T. G. performed data management and analysis. Y. B. C. advised on the statistical analysis. P. H. W., S. L. L., Y. B. C., N. L., J. K. Y. C., M. F.-F. C. and F. Y. interpreted the findings. P. H. W. drafted the paper. All the authors participated in the critical review, revision and approval of the final manuscript.

P. D. G., K. M. G. and Y.-S. C. report receiving reimbursement for speaking at conferences sponsored by companies selling nutritional products. P. D. G., K. M. G. and Y.-S. C. report being part of an academic consortium that has received research funding from Abbott Nutrition, Nestle and Danone. No other disclosures were reported.

\section{Supplementary material}

For supplementary material/s referred to in this article, please visit https://doi.org/10.1017/S0007114517001684

\section{References}

1. Gluckman PD \& Hanson MA (2006) The developmental origins of health and disease: an overview. In Developmental Origins of Health and Disease, pp. 1-5 [PD Gluckman and MA Hanson, editors]. Cambridge: Cambridge University Press.

2. Hanson M, Godfrey KM, Lillycrop KA, et al. (2004) Developmental plasticity and developmental origins of non-communicable disease: theoretical considerations and epigenetic mechanisms. Prog Biophys Mol Biol 106, 272-280.

3. Carolan-Olah M, Duarte-Gardea M \& Lechuga J (2015) A critical review: early life nutrition and prenatal programming for adult disease. J Clin Nurs 24, 3716-3729.

4. Lillycrop KA (2011) Effect of maternal diet on the epigenome: implications for human metabolic disease. Proc Nutr Soc 70, 64-72.

5. Mühlhäusler BS, Adam CL \& McMillen IC (2008) Maternal nutrition and the programming of obesity. Organogenesis $\mathbf{4}$, 144-152.

6. Mcmillen IC \& Robinson JS (2005) Developmental origins of the metabolic syndrome: prediction, plasticity, and programming. Physiol Rev 85, 571-633. 
7. Godfrey KM, Lillycrop KA, Burdge GC, et al. (2007) Epigenetic mechanisms and the mismatch concept of the developmental origins of health and disease. Pediatr Res 61, 5R-10R.

8. Gluckman PD \& Hanson MA (2004) Developmental origins of disease paradigm: a mechanistic and evolutionary perspective. Pediatr Res 56, 311-317.

9. Mason JB, Shrimpton R, Saldanha LS, et al. (2015) The first 500 days of life: policies to support maternal nutrition. Glob Health Action 7, 23623.

10. Schwartz C, Scholtens PAMJ, Lalanne A, et al. (2011) Development of healthy eating habits early in life. Review of recent evidence and selected guidelines. Appetite 57, 796-807.

11. Galland BC, Taylor BJ, Elder DE, et al. (2012) Normal sleep patterns in infants and children: a systematic review of observational studies. Sleep Med Rev 16, 213-222.

12. Yan J, Liu L, Zhu Y, et al. (2014) The association between breastfeeding and childhood obesity: a meta-analysis. BMC Public Health 14, 1267.

13. Novotny R, Coleman P, Tenorio L, et al. (2007) Breastfeeding is associated with lower body mass index among children of the Commonwealth of the Northern Mariana Islands. $J$ Am Diet Assoc 107, 1743-1746.

14. Skinner JD, Bounds W, Carruth BR, et al. (2004) Predictors of children's body mass index: a longitudinal study of diet and growth in children aged 2-8y. Int J Obes Relat Metab Disord 28, 476-482.

15. Ong KK, Emmett PM, Noble S, et al. (2006) Dietary energy intake at the age of 4 months predicts postnatal weight gain and childhood body mass index. Pediatrics 117, e503.

16. Fonken LK, Workman JL, Walton JC, et al. (2010) Light at night increases body mass by shifting the time of food intake. Proc Natl Acad Sci U S A 107, 18664-18669.

17. Arble DM, Bass J, Laposky AD, et al. (2009) Circadian timing of food intake contributes to weight gain. Obesity 17, 2100-2102.

18. Gallant AR, Lundgren J \& Drapeau V (2012) The night-eating syndrome and obesity. Obes Rev 13, 528-536.

19. Ma Y, Bertone ER, Stanket EJ III, et al. (2003) Association between eating patterns and obesity in a free-living US adult population. Am J Epidemiol 158, 85-92.

20. Watanabe Y, Saito I, Henmi I, et al. (2014) Skipping breakfast is correlated with obesity. J Rural Med 9, 51-58.

21. Szajewska H \& Ruszczynski M (2010) Systematic review demonstrating that breakfast consumption influences body weight outcomes in children and adolescents in Europe. Crit Rev Food Sci Nutr 50, 113-119.

22. Berkey CS, Rockett HRH, Gillman MW, et al. (2003) Longitudinal study of skipping breakfast and weight change in adolescents. Int J Obes Relat Metab Disord 27, 1258-1266.

23. Horikawa C, Kodama S, Yachi Y, et al. (2011) Skipping breakfast and prevalence of overweight and obesity in Asian and Pacific regions: a meta-analysis. Prev Med 53, 260-267.

24. Soh SE, Tint MT, Gluckman PD, et al. (2014) Cohort profile: Growing Up in Singapore Towards healthy Outcomes (GUSTO) birth cohort study. Int J Epidemiol 43, 1401-1409.

25. World Health Organization (2004) Appropriate body-mass index for Asian populations and its implications for policy and intervention strategies. Lancet 363, 157-163.

26. de Onis M., Garza C, Victora CG, et al. (2004) The WHO Multicentre Growth Reference Study: planning, study design, and methodology. Food Nutr Bull 25, S15-S16.

27. Cheng TS, Loy SL, Cheung YB, et al. (2016) Sexually dimorphic response to feeding mode in the growth of infants. Am J Clin Nutr 103, 398-405.
28. World Health Organization (2008) Training Course on Child Growth Assessment, WHO Child Growth Standards, C Interpreting Growth Indicators. Geneva: Department of Nutrition for Health and Development.

29. Sadeh A (2004) A brief screening questionnaire for infant sleep problems: validation and findings for an Internet sample. Pediatrics 113, e570-e577.

30. Ahluwalia N, Dwyer J, Terry A, et al. (2016) Update on NHANES dietary data: focus on collection, release, analytical considerations, and uses to inform public policy. Adv Nutr 7 , 121-134.

31. Health Promotion Board Singapore (2012) Singapore: healthy living and disease prevention information. http://www.hpb. gov.sg/HOPPortal/ (accessed September 2016).

32. United States Department of Agriculture (2011) NDL/FNIC Food Composition Database: USDA national nutrient database for standard reference. http://ndb.nal.usda.gov/ (accessed September 2016).

33. Suwazono Y, Dochi M, Sakata K, et al. (2008) A longitudinal study on the effect of shift work on weight gain in male Japanese workers. Obesity 16, 1887-1893.

34. Gan Y, Yang C, Tong X, et al. (2015) Shift work and diabetes mellitus: a meta-analysis of observational studies. Oсcup Environ Med 72, 72-78.

35. Colles SL, Dixon JB \& O'Brien PE (2007) Night eating syndrome and nocturnal snacking: association with obesity, binge eating and psychological distress. Int J Obes 31, 1722-1730.

36. Smith KJ, Gall SL, McNaughton SA, et al. (2010) Skipping breakfast: longitudinal associations with cardiometabolic risk factors in the Childhood Determinants of Adult Health Study. Am J Clin Nutr 92, 1316-1325.

37. Mohawk JA, Green CB \& Takahashi JS (2012) Central and peripheral circadian clocks in mammals. Annu Rev Neurosci 35, 445-462.

38. Longo VD \& Panda S (2016) Fasting, circadian rhythms, and time-restricted feeding in healthy lifespan. Cell Metab 23, 1048-1059.

39. Laplante M \& Sabatini DM (2012) mTOR signaling in growth control and disease. Cell 149, 274-293.

40. Wang JB, Patterson RE, Ang A, et al. (2014) Timing of energy intake during the day is associated with the risk of obesity in adults. J Hum Nutr Diet 27, Suppl. 2, 255-262.

41. Jakubowicz D, Barnea M, Wainstein J, et al. (2013) High caloric intake at breakfast vs. dinner differentially influences weight loss of overweight and obese women. Obesity $\mathbf{2 1}$, 2504-2512

42. Gluck ME, Venti CA, Salbe AD, et al. (2008) Nighttime eating: commonly observed and related to weight gain in an inpatient food intake study. Am J Clin Nutr 88, 900-905.

43. McDonald L, Wardle J, Llewellyn CH, et al. (2015) Sleep and nighttime energy consumption in early childhood: a population-based cohort study. Pediatr Obes 10, 454-460.

44. Perera PJ, Fernando M, Warnakulasuria T, et al. (2011) Feeding practices among children attending child welfare clinics in Ragama $\mathrm{MOH}$ area: a descriptive crosssectional study. Int Breastfeed J 6, 18.

45. Health Promotion Board Singapore (2012) Recommended dietary allowances. https://www.hpb.gov.sg/HOPPortal/healtharticle/2652/ (accessed September 2016).

46. Ma Y, Olendzki BC, Li W, et al. (2006) Seasonal variation in food intake, physical activity, and body weight in a predominantly overweight population. Eur J Clin Nutr 60, 519-528.

47. Shahar DR, Yerushalmi N, Lubin F, et al. (2001) Seasonal variations in dietary intake affect the consistency of dietary assessment. Eur J Epidemiol 17, 129-133. 